Sociologias, Porto Alegre, ano 8, № 16, jul/dez 2006, p. 20-45

\title{
Políticas Públicas: uma revisão da literatura ${ }^{2}$
}

CEINA SOUA*

\section{Introdução}

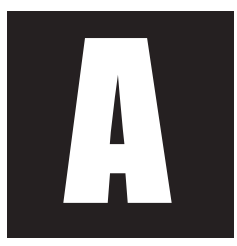

s últimas décadas registraram o ressurgimento da importância do campo de conhecimento denominado políticas públicas, assim como das instituições, regras e modelos que regem sua decisão, elaboração, implementação e avaliação. Vários fatores contribuíram para a maior visibilidade desta área. 0 primeiro foi a adoção de políticas restritivas de gasto, que passaram a dominar a agenda da maioria dos países, em especial os em desenvolvimento. A partir dessas políticas, o desenho e a execução de políticas públicas, tanto as econômicas como as sociais, ganharam maior visibilidade. 0 segundo fator é que novas visões sobre o papel dos governos substituíram as políticas keynesianas do pós-guerra por políticas restritivas de gasto. Assim, do ponto de vista da política pública, o ajuste fiscal implicou a adoção de orçamentos equilibrados entre receita e despesa e restrições à intervenção do Estado na economia e nas políticas sociais. Esta agenda passou a dominar corações e mentes a partir dos anos 80, em especial em países com longas e recorrentes trajetórias inflacionárias como os da América Latina. 0 terceiro fator, mais diretamente relacionado aos países em desenvolvimento e de democracia recente ou recém-democrati-

* Phd em Ciência Política pela London School of Economics and Political Science (LSE). Pesquisadora do Centro de Recursos Humanos (CRH) da U niversidade Federal da Bahia. Brasil.

1 Este artigo é uma versão revista e ampliada de texto publicado anteriormente. Ver Souza (2003). 
zados, é que, na maioria desses países, em especial os da América Latina, ainda não se conseguiu formar coalizões políticas capazes de equacionar minimamente a questão de como desenhar políticas públicas capazes de impulsionar o desenvolvimento econômico e de promover a inclusão social de grande parte de sua população. Respostas a este desafio não são fáceis nem claras ou consensuais. Elas dependem de muitos fatores externos e internos. No entanto o desenho das políticas públicas e as regras que regem suas decisões, elaboração e implementação, também influenciam os resultad os dos conflitos inerentes às decisões sobre política pública.

Este artigo trata dos principais conceitos e modelos de análise de políticas públicas, buscando sintetizar o estado-da-arte da área, ou seja, mapear como a literatura clássica e a mais recente tratam o tema. 0 artigo busca também construir algumas pontes entre as diferentes vertentes das teorias neo-institucionalistas e a análise de políticas públicas. No entanto o objetivo do artigo é modesto: tentar minimizar a lacuna da ainda escassa tradução para a língua portuguesa da literatura sobre políticas públicas e, ao rever as principais formulações teóricas e conceituais mais próximas da literatura específica sobre políticas públicas e da literatura neo-institucionalista, contribuir para seu teste empírico nas pesquisas sobre políticas públicas brasileiras.

0 texto está dividido em duas partes. A primeira introduz os principais conceitos, modelos analíticos e tipologias específicos da área de políticas públicas. A segunda discute as possibilidades de aplicação da literatura neo-institucionalista à análise de políticas públicas.

\section{Como e por que surgiu a área de políticas públicas?}

Entender a origem e a ontologia de uma área do conhecimento é importante para melhor compreender seus desdobramentos, sua trajetória e suas perspectivas. A política pública enquanto área de conhecimento e 
Sociologias, Porto Alegre, ano 8, № 16, jul/dez 2006, p. 20-45

disciplina acadêmica nasce nos EU A, rompendo ou pulando as etapas seguidas pela tradição européia de estudos e pesquisas nessa área, que se concentravam, então, mais na análise sobre o Estado e suas instituições do que na produção dos governos. Assim, na Europa, a área de política pública vai surgir como um desdobramento dos trabalhos baseados em teorias explicativas so bre o papel do Estado e de uma das mais importantes instituições do Estado - o governo -, produtor, por excelência, de políticas públicas. N osEUA, ao contrário, a área surge no mundo acadêmico sem estabelecer relações com as bases teóricas sobre o papel do Estado, passando direto para a ênfase nos estudos sobre a ação dos governos.

0 pressuposto analítico que regeu a constituição e a consolidação dos estudos sobre políticas públicas é o de que, em democracias estáveis, aquilo que o governo faz ou deixa de fazer é passível de ser (a) formulado cientificamente e (b) analisado por pesquisadores independentes. A trajetória da disciplina, que nasce como subárea da ciência política, abre o terceiro grande caminho trilhado pela ciência política norte-americana no que se refere ao estudo do mundo público. 0 primeiro, seguindo a tradição de Madison, cético da natureza humana, focalizava o estudo das instituições, consideradas fundamentais para limitar a tirania e as paixões inerentes à natureza humana. 0 segundo caminho seguiu a tradição de Paine e Tocqueville, que viam, nas organizações locais, a virtude cívica para promover o "bom" governo. 0 terceiro caminho foi o das políticas públicas como um ramo da ciência política para entender como e por que os governos optam por determinadas ações.

$\mathrm{Na}$ área do governo propriamente dito, a introdução da política pública como ferramenta das decisões do governo é produto da Guerra Fria e da valorização da tecnocracia como forma de enfrentar suas conseqüências. Seu introdutor no governo dos EU A foi Robert M cN amara que estimulou a criação, em 1948, da RAND Corporation, organização não-governamental 
financiada por recursos públicos e considerada a precursora dos think tanks. 0 trabalho do grupo de matemáticos, cientistas políticos, analistas de sistema, engenheiros, sociólogos etc., influenciados pela teoria dos jogos de Neuman, buscava mostrar como uma guerra poderia ser conduzida como um jogo racional. A proposta de aplicação de métodos científicos às formulações e às decisões do governo sobre problemas públicos se expande depois para outras áreas da produção governamental, inclusive para a política social. ${ }^{2}$

\section{O s "pais" fundadores da área de políticas públicas}

Considera-se que a área de políticas públicas contou com quatro grandes "pais" fundadores: H. Laswell, H. Simon, C. Lindblom e D. Easton.

Laswell (1936) introduz a expressão policy analysis (análise de política pública), ainda nos anos 30, como forma de conciliar conhecimento científico/acadêmico com a produção empírica dos governos e também como forma de estabelecer o diálogo entre cientistas sociais, grupos de interesse e governo.

Simon (1957) introduziu o conceito de racionalidade limitada dos decisores públicos (policy makers), argumentando, todavia, que a limitação da racionalidade poderia ser minimizada pelo conhecimento racional. Para Simon, a racionalidade dos decisores públicos é sempre limitada por problemas tais como informação incompleta ou imperfeita, tempo para a tomada de decisão, auto-interesse dos decisores, etc., mas a racionalidade, segundo Simon, pode ser maximizada até um ponto satisfatório pela criação de estruturas (conjunto de regras e incentivos) que enquadre o comportamento dos atores e modele esse comportamento na direção de re-

2 Para uma síntese desta trajetória, ver Parsons (1997: 278-8) 
Sociologias, Porto Alegre, ano 8, ํo 16, jul/dez 2006, p. 20-45

sultados desejados, impedindo, inclusive, a busca de maximização de interesses próprios.

Lindblom (1959; 1979) questionou a ênfase no racionalismo de Laswell e Simon e propôs a incorporação de outras variáveis à formulação e à análise de políticas públicas, tais como as relações de poder e a integração entre as diferentes fases do processo decisório o que não teria necessariamente um fim ou um princípio. Daí por que as políticas públicas precisariam incorporar outros elementos à sua formulação e à sua análise além das questões de racionalidade, tais como o papel das eleições, das burocracias, dos partidos e dos grupos de interesse.

Easton (1965) contribuiu para a área ao definir a política pública como um sistema, ou seja, como uma relação entre formulação, resultados e 0 ambiente. Segundo Easton, políticas públicas recebem inputsdos partidos, da mídia e dos grupos de interesse, que influenciam seus resultados e efeitos.

\section{O que são políticas públicas}

Não existe uma única, nem melhor, definição sobre o que seja política pública. Mead (1995) a define como um campo dentro do estudo da política que analisa o governo à luz de grandes questões públicas e Lynn (1980), como um conjunto de ações do governo que irão produzir efeitos específicos. Peters (1986) segue o mesmo veio: política pública é a soma das atividades dos governos, que agem diretamente ou através de delegação, e que influenciam a vida dos cidadãos. Dye (1984) sintetiza a definição de política pública como "o que o governo escolhe fazer ou não fazer". ${ }^{3}$ A definição mais conhecida continua sendo a de Laswell, ou seja, decisões e análises sobre política pública implicam responder às seguintes questões: quem ganha o quê, por quê e que diferença faz.

3 Há mais de 40 anos atrás, Bachrach e Baratz (1962) mostraram que não fazer nada em relação a um problema também é uma forma de política pública. 
O utras definições enfatizam o papel da política pública na solução de problemas. Críticos dessas definições, que superestimam aspectos racionais e procedimentais das políticas públicas, argumentam que elas ignoram a essência da política pública, isto é, o embate em torno de idéias e interesses. Pode-se também acrescentar que, por concentrarem o foco no papel dos governos, essas definições deixam de lado o seu aspecto conflituoso e os limites que cercam as decisões dos governos. Deixam também de fora possibilidades de cooperação que podem ocorrer entre os governos e outras instituições e grupos sociais.

No entanto definições de políticas públicas, mesmo as minimalistas, guiam o nosso olhar para o locus onde os embates em torno de interesses, preferências e idéias se desenvolvem, isto é, os governos. Apesar de optar por abordagens diferentes, as definições de políticas públicas assumem, em geral, uma visão holística do tema, uma perspectiva de que o todo é mais importante do que a soma das partes e que indivíduos, instituições, interações, ideologia e interesses contam, mesmo que existam diferenças sobre a importância relativa destes fatores.

Assim, do ponto de vista teórico-conceitual, a política pública em geral e a política social em particular são campos multidisciplinares, e seu foco está nas explicações sobre a natureza da política pública e seus processos. Por isso, uma teoria geral da política pública implica a busca de sintetizar teorias construídas no campo da sociologia, da ciência política e da economia. As políticas públicas repercutem na economia e nas sociedades, daí por que qualquer teoria da política pública precisa também explicar as inter-relações entre Estado, política, economia e sociedade. Tal é também a razão pela qual pesquisadores de tantas disciplinas - economia, ciência política, sociologia, antropologia, geografia, planejamento, gestão e ciências sociais aplicadas - partilham um interesse comum na área e têm contribuído para avanços teóricos e empíricos. 
Sociologias, Porto Alegre, ano 8, № 16, jul/dez 2006, p. 20-45

Pode-se, então, resumir política pública como o campo do conhecimento que busca, ao mesmo tempo, "colocar o governo em ação" e/ou analisar essa ação (variável independente) e, quando necessário, propor mudanças no rumo ou curso dessas ações (variável dependente). A formulação de políticas públicas constitui-se no estágio em que os governos democráticos traduzem seus propósitos e plataformas eleitorais em programas e ações que produzirão resultados ou mudanças no mundo real.

Se admitirmos que a política pública é um campo holístico, isto é, uma área que situa diversas unidades em totalidades organizadas, isso tem duas implicações. A primeira é que, como referido acima, a área torna-se território de várias disciplinas, teorias e modelos analíticos. Assim, apesar de possuir suas próprias modelagens, teoriase métodos, a política pública, embora seja formalmente um ramo da ciência política, a ela não se resume, podendo também ser objeto analítico de outras áreas do conhecimento, inclusive da econometria, já bastante influente em uma das subáreas da política pública, a da avaliação, que também vem recebendo influência de técnicas quantitativas. A segunda é que o caráter holístico da área não significa que ela careça de coerência teórica e metodológica, mas sim que ela comporta vários “olhares". Por último, políticas públicas, após desenhadas e formuladas, desdobram-se em planos, programas, projetos, bases de dados ou sistema de informação e pesquisas. ${ }^{4} \mathrm{Q}$ uando postas em ação, são implementadas, ficando daí submetidas a sistemas de acompanhamento e avaliação.

\section{O papel dos governos}

Debates sobre políticas públicas implicam responder à questão sobre o espaço que cabe aos governos na definição e implementação de políticas públicas. Não se defende aqui que o Estado (ou os governos que decidem

4 Muitas vezes, a política pública também requer a aprovação de nova legislação. 
e implementam políticas públicas ou outras instituições que participam do processo decisório) reflete tão-somente as pressões dos grupos de interesse, como diria a versão mais simplificada do pluralismo. Também não se defende que o Estado opta sempre por políticas definidas exclusivamente por aqueles que estão no poder, como nas versões também simplificadas do elitismo, nem que servem apenas aos interesses de determinadas classes sociais, como diriam as concepções estruturalistas e funcionalistas do Estado. No processo de definição de políticas públicas, sociedades e Estados complexos como os constituídos no mundo moderno estão mais próximos da perspectiva teórica daqueles que defendem que existe uma "autonomia relativa do Estado", o que faz com que o mesmo tenha um espaço próprio de atuação, embora permeável a influências externas e internas (Evans, Rueschmeyer e Skocpol, 1985). Essa autonomia relativa gera determinadas capacidades, as quais, por sua vez, criam as condições para a implementação de objetivos de políticas públicas. A margem dessa "autonomia" e o desenvolvimento dessas "capacidades" dependem, obviamente, de muitos fatores e dos diferentes momentos históricos de cada país.

Apesar do reconhecimento de que outros segmentos que não os governos se envolvem na formulação de políticas públicas, tais como os grupos de interesse e os movimentos sociais, cada qual com maior ou menor influência a depender do tipo de política formulada e das coalizões que integram o governo, e apesar de uma certa literatura argumentar que 0 papel dos governos tem sido encolhido por fenômenos como a globalização, a diminuição da capacidade dos governos de intervir, formular políticas públicas e de governar não está empiricamente comprovada. Visões menos ideologizadas defendem que, apesar da existência de limitações e constrangimentos, estes não inibem a capacidade das instituições governamentais de governar a sociedade (Peters, 1998: 409), apesar de tornar a atividade de governar e de formular políticas públicas mais complexa. 
Sociologias, Porto Alegre, ano 8, ํo 16, jul/dez 2006, p. 20-45

\section{Modelos de formulação e análise de políticas públicas}

Dentro do campo específico da política pública, alguns modelos explicativos foram desenvolvidos para se entender melhor como e por que o governo faz ou deixa de fazer alguma ação que repercutirá na vida dos cidadãos. Muitos foram os modelos desenvolvidos e aqui serão mapeados apenas os principais.

O tipo da política pública

Theodor Lowi $(1964 ; 1972)$ desenvolveu a talvez mais conhecida tipologia sobre política pública, elaborada através de uma máxima: a política pública faz a política. Com essa máxima Lowi quis dizer que cada tipo de política pública vai encontrar diferentes formas de apoio e de rejeição e que disputas em torno de sua decisão passam por arenas diferenciadas. Para Lowi, a política pública pode assumir quatro formatos. 0 primeiro é 0 das políticas distributivas, decisões tomadas pelo governo, que desconsideram a questão dos recursos limitados, gerando impactos mais individuais do que universais, ao privilegiar certos grupos sociais ou regiões, em detrimento do todo. 0 segundo é o das políticas regulatórias, que são mais visíveis ao público, envolvendo burocracia, políticos e grupos de interesse. 0 terceiro é o das políticas redistributivas, que atinge maior número de pessoas e impõe perdas concretas e no curto prazo para certos grupos sociais, e ganhos incertos e futuro para outros; são, em geral, as políticas sociais universais, o sistema tributário, o sistema previdenciário e são as de mais difícil encaminhamento. 0 quarto é o das políticas constitutivas, que lidam com procedimentos. Cada uma dessas políticas públicas vai gerar pontos ou grupos de vetos e de apoios diferentes, processando-se, portanto, dentro do sistema político de forma também diferente.

5 Para maiores detalhes sobre diversos modelos analíticos, ver Goodin e Klingemann (1998), em especial o capítulo 7, Parsons (1997), Sabatier (1999) e Theodoulou e Cahn (1995). Vários sites disponibilizam estudosempíricos sobre políticas públicas, com destaque para http:// www.policylibrary.com. 
Incrementalismo

A visão da política pública como um processo incremental foi desenvolvida por Lindblom (1979), Caiden e W ildavsky (1980) e W ildavisky (1992). Baseados em pesquisas empíricas, os autores argumentaram que os recursos governamentais para um programa, órgão ou uma dada política pública não partem do zero e sim, de decisões marginais e incrementais que desconsideram mudanças políticas ou mudanças substantivas nos programas públicos. Assim, as decisões dos governos seriam apenas incrementais e pouco substantivas. A visão incrementalista da política pública perdeu parte do seu poder explicativo com as profundas reformas ocorridas em vários países, provocadas pelo ajuste fiscal. No entanto os que trabalham nos governos e os que pesquisam os orçamentos públicos conhecem bem a força do incrementalismo, que mantém intactos estruturas governamentais e recursos para políticas públicas que deixaram de estar na agenda dos governos. Mas é do incrementalismo que vem a visão de que decisões tomadas no passado constrangem decisões futuras e limitam a capacidade dos governos de adotar novas políticas públicas ou de reverter a rota das políticas atuais.

O ciclo da política pública

Esta tipologia vê a política pública como um ciclo deliberativo, formado por vários estágios e constituindo um processo dinâmico e de aprendizado. 0 ciclo da política pública é constituído dos seguintes estágios: definição de agenda, identificação de alternativas, avaliação das opções, seleção das opções, implementação e avaliação.

Esta abordagem enfatiza sobremodo a definição de agenda (agenda setting) e pergunta por que algumas questões entram na agenda política, enquanto outras são ignoradas. Algumas vertentes do ciclo da política pública focalizam mais os participantes do processo decisório, e outras, o pro- 
Sociologias, Porto Alegre, ano 8, № 16, jul/dez 2006, p. 20-45

cesso de formulação da política pública. Cada participante e cada processo podem atuar como um incentivo ou como um ponto de veto. À pergunta de como os governos definem suas agendas, são dados três tipos de respostas. A primeira focaliza os problemas, isto é, problemas entram na agenda quando assumimos que devemos fazer algo sobre eles. 0 reconhecimento e a definição dos problemas afeta os resultados da agenda. A segunda resposta focaliza a política propriamente dita, ou seja, como se constrói a consciência coletiva sobre a necessidade de se enfrentar um dado problema. Essa construção se daria via processo eleitoral, via mudanças nos partidos que governam ou via mudanças nas ideologias (ou na forma de ver 0 mundo), aliados à força ou à fraqueza dos grupos de interesse. Segundo esta visão, a construção de uma consciência coletiva sobre determinado problema é fator poderoso e determinante na definição da agenda. Q uando o ponto de partida da política pública é dado pela política, o consenso é construído mais por barganha do que por persuasão, ao passo que, quando 0 ponto de partida da política pública encontra-se no problema a ser enfrentado, dá-se o processo contrário, ou seja, a persuasão é a forma para a construção do consenso. A terceira resposta focaliza os participantes, que são classificados como visíveis, ou seja, políticos, mídia, partidos, grupos de pressão, etc. e invisíveis, tais como acadêmicose burocracia. Segundo esta perspectiva, os participantes visíveis definem a agenda e os invisíveis, as alternativas. 0 modelo "garbage can"

0 modelo garbage can ou "lata de lixo" foi desenvolvido por Cohen, March e O Isen (1972), argumentando que escolhas de políticas públicas são feitas como se as alternativas estivessem em uma "lata de lixo". O u seja, existem vários problemas e poucas soluções. As soluções não seriam detidamente analisadas e dependeriam do leque de soluções que os decisores (policy makers) têm no momento. Segundo este modelo, as organizações são formas anárquicas que compõem um conjunto de idéias com 
pouca consistência. As organizações constroem as preferências para a solução dos problemas - ação - e não, as preferências constroem a ação. A compreensão do problema e das soluções é limitada, e as organizações operam em um sistema de tentativa e erro. Em síntese, o modelo advoga que soluções procuram por problemas. As escolhas compõem um garbage can no qual vários tipos de problemas e soluções são colocados pelos participantes à medida que eles aparecem. Esta abordagem foi aplicada por Kingdon (1984), combinando também elementos do ciclo da política pública, em especial a fase de definição de agenda (agenda setting), constituindo o que se classifica como um outro modelo, o de multiple streams, ou "múltiplas correntes". ${ }^{6}$

Coalizão de defesa

O modelo da coalizão de defesa (advocacy coalition), de Sabatier e Jenkins-Smith (1993), discorda da visão da política pública trazida pelo ciclo da política e pelo garbage can por sua escassa capacidade explicativa sobre por que mudanças ocorrem nas políticas públicas. Segundo estes autores, a política pública deveria ser concebida como um conjunto de subsistemas relativamente estáveis, que se articulam com os acontecimentos externos, os quais dão os parâmetros para os constrangimentose os recursos de cada política pública. Contrariando o modelo do garbage can, Sabatier e JenkinsSmith defendem que crenças, valores e idéias são importantes dimensões do processo de formulação de políticas públicas, em geral ignorados pelos modelos anteriores. Assim, cada subsistema que integra uma política pública é composto por um número de coalizões de defesa que se distinguem pelos seus valores, crenças e idéias e pelos recursos de que dispõem. ${ }^{7}$

60 modelo analítico de Kingdon foi recentemente testado no Brasil em algumasteses de doutorado. Ver, por exemplo, Capella (2005) e Pinto (2004).

7 Este modelo foi aplicado por Bueno (2005). 
Sociologias, Porto Alegre, ano 8, ํo 16, jul/dez 2006, p. 20-45

Arenas sociais

O modelo de arenas sociais vê a política pública como uma iniciativa dos chamados empreendedores políticos ou de políticas públicas. Isto porque, para que uma determinada circunstância ou evento se transforme em um problema, é preciso que as pessoas se convençam de que algo precisa ser feito. É quando os policy makers do governo passam a prestar atenção em algumas questões e a ignorar outras. Existiriam três principais mecanismos para chamar a atenção dos decisores e formuladores de políticas públicas: (a) divulgação de indicadores que desnudam a dimensão do problema; (b) eventos tais como desastres ou repetição continuada do mesmo problema; e (c) feedback, ou informações que mostram as falhas da política atual ou seus resultados medíocres. Esses empreendedores constituem a policy community, comunidade de especialistas, pessoas que estão dispostas a investir recursos variados esperando um retorno futuro, dado por uma política pública que favoreça suas demandas. Eles são cruciais para a sobrevivência e o sucesso de uma idéia e para colocar o problema na agenda pública.

Esses empreendedores podem constituir, e em geral constituem, redes sociais. ${ }^{8}$ Redes envolvem contatos, vínculos e conexões que relacionam os agentes entre si e não se reduzem às propriedades dos agentes individuais. As instituições, a estrutura social e as características de indivíduos e grupos são cristalizações dos movimentos, trocas e "encontros" entre as entidades nas múltiplas e intercambiantes redes que se ligam ou que se superpõem. 0 foco está no conjunto de relações, vínculos e trocas entre entidades e indivíduos e não, nas suas características. Este método e referencial teórico partem do estudo de situações concretas para investigar a integração entre as estruturas presentes e as ações, estratégias, constrangimentos, identidades e valores. As redes constrangem as ações e as estra-

8 A literatura internacional sobre redes sociais é ampla e diversificada. Para uma revisão dessa literatura em português, ver Marques (2000). 
tégias, mas também as constroem e reconstroem continuamente. A força deste modelo está na possibilidade de investigação dos padrões das relações entre indivíduos e grupos. ${ }^{9}$

Modelo do "equilíbrio interrompido"

O modelo do "equilíbrio interrompido" (punctuated equilibium) foi elaborado por Baumgartner e Jones (1993), baseado em noções de biologia e computação. Da biologia veio a noção de "equilíbrio interrompido", isto é, a política pública se caracteriza por longos períodos de estabilidade, interrompidos por períodos de instabilidade que geram mudanças nas políticas anteriores. Da computação e dos trabalhos de Simon, vem a noção de que os seres humanos têm capacidade limitada de processar informação, daí por que as questões se processam paralelamente e não, de forma serial, ou seja, uma de cada vez. O s subsistemas de uma política pública permitem ao sistema político-decisório processar as questões de forma paralela, ou seja, fazendo mudanças a partir da experiência de implementação e de avaliação, e somente em períodos de instabilidade ocorre uma mudança serial mais profunda. Este modelo, segundo os autores, permite entender por que um sistema político pode agir tanto de forma incremental, isto é, mantendo o status quo, como passar por fases de mudanças mais radicais nas políticas públicas. Fundamental ao modelo é a construção de uma imagem sobre determinada decisão ou política pública (policy image), e a mídia teria papel preponderante nessa construção. ${ }^{10}$

9 M arques (2000) analisa a formulação de políticas na área de saneamento básico na Região M etropolitana do Rio de Janeiro, através do modelo das redes sociais. Sua pesquisa mostra que, ao contrário do padrão norte-americano de lobbies ou do corporativismo socialdemocrata europeu, a intermediação de interesses ocorre aqui de forma disseminada por inúmeros e diversos contatos pessoais entre os integrantes do governo e os interesses privados, intermediada por uma policy community. Também o papel desempenhado por um grupo de médicos sanitaristas que se organizou em torno da reforma do sistema de saúde pública no Brasil, no sentido da sua universalização e descentralização, é um bom exemplo das possibilidades explicativas saúde pública no Brasil, no sentido da sua universalização e descentralização, e um bom exemplo das possibilidades explicativas
desse modelo.

10 Pesquisa realizada por Fucks (1998) testa esse modelo analisando a inserção da temática ambiental no Rio de Janeiro. 
Sociologias, Porto Alegre, ano 8, ํo 16, jul/dez 2006, p. 20-45

Modelos influenciados pelo "novo gerencialismo público" e pelo ajuste fiscal

A partir da influência do que se convencionou chamar de "novo gerencialismo público" e da política fiscal restritiva de gasto, adotada por vários governos, novos formatos foram introduzidos nas políticas públicas, todos voltados para a busca de eficiência. Assim, a eficiência passou a ser vista como o principal objetivo de qualquer política pública, aliada à importância do fator credibilidade e à delegação das políticas públicas para instituições com "independência" política. Estes novos formatos, que guiam hoje o desenho das políticas públicas mais recentes, ainda são pouco incorporados nas pesquisas empíricas.

A ênfase na eficiência nasceu da premissa de que as políticas públicas e suas instituições estavam fortemente influenciadas por visões redistributivas ou distributivas, na linguagem de Lowi, desprezando-se a questão da sua eficiência. As razões para tal reconhecimento estão na crise fiscal e ideológica do Estado, aliadas ao declínio do sonho pluralista que caracterizou a visão norte-americana sobre políticas públicas em décadas passadas. ${ }^{11} 0$ primeiro grande ataque às possibilidades das ações coletivas e no qual decisões sobre políticas públicas podem ser situadas, veio de O Ison (1965), ao afirmar que interesses comuns, os quais, em princípio, guiariam o processo decisório que afetam os indivíduos, não resultam necessariamente em ação coletiva e sim em free riding, pois os interesses de poucos têm mais chances de se organizarem do que os interesses difusos de muitos. Existe, segundo O Ison, um interesse público que não é a soma dos interesses dos grupos. Assim, a "boa" política pública não poderia resultar da disputa entre grupos, mas de uma análise racional. Como conseqüência, embora indireta, do influente trabalho de $\mathrm{O}$ Ison, passou-se a enfatizar a questão da eficiência/

$11 \mathrm{~N}$ a versão mais idealizada do pluralismo, a política pública resultaria do equilíbrio alcançado na luta entre grupos de interesse concorrentes. 
racionalidade das políticas públicas, que seria alcançada por novas políticas voltadas, por exemplo, para a desregulamentação, privatização e para reformas no sistema social, as quais, afirma-se, poderiam diminuiriam os riscos da ação coletiva.

O elemento credibilidade das políticas públicas também ganhou importância, ou seja, a prevalência de regras pré-anunciadas seria mais eficiente do que o poder discricionário de políticos e burocratas, contido nas políticas públicas. 0 fator credibilidade passou a ser fundamental para políticas como a monetária, mas também influenciou o novo desenho das políticas públicas em várias outras áreas. A credibilidade baseia-se na existência de regras claras em contraposição à discricionariedade dos decisores públicos e burocratas, a qual levaria à inconsistência. Além do mais, a discricionariedade gera altos custos de transação. Assim, a discricionariedade, de acordo com esta visão, seria minimizada ou eliminada, delegando poder a instituições bem desenhadas e "independentes" do jogo político e fora da influência dos ciclos eleitorais.

A delegação para órgãos "independentes" nacionais, mas também internacionais, passou a ser outro elemento importante no desenho das políticas públicas. Mas por que os políticos (governantes e parlamentares) abririam mão do seu poder? A resposta estaria na credibilidade desses órgãos "independentes" devido à experiência técnica de seus membros e para que as regras não fossem, aqui também, submetidas às incertezas dos ciclos eleitorais, mantendo sua continuidade e coerência. ${ }^{12}$

Concorrendo com a influência do "novo gerencialismo público" nas políticas públicas, existe uma tentativa, em vários países do mundo em desenvolvimento, de implementar políticas públicas de caráter participativo. Impulsionadas, por um lado, pelas propostas dos organismos multilaterais e,

12 Exemplos da influência desta nova visão sobre as políticas públicas já são abundantes, destacando-se a relevância assumida pela O M C - O rganização M undial do Comércio - e pelas O NGs, assim como a defesa de mandato por tempo determinado para os diretores das agências de regulação e a defesa da "independência" operacional ou autonomia dos Bancos centrais. 
Sociologias, Porto Alegre, ano 8, no 16, jul/dez 2006, p. 20-45

por outro, por mandamentos constitucionais e pelos compromissos assumidos por alguns partidos políticos, várias experiências foram implementadas visando à inserção de grupos sociais e/ou de interesses na formulação e acompanhamento de políticas públicas, principalmente nas políticas sociais. No Brasil, são exemplos dessa tentativa os diversos consel hos comunitários voltados para as políticas sociais, assim como o O rçamento Participativo. Fóruns decisórios como conselhos comunitários e 0 rçamento Participativo seriam os equivalentes políticos da eficiência.

Apesar da aceitação de várias teses do "novo gerencialismo público" e da experimentação de delegação de poder para grupos sociais comunitários e/ou que representam grupos de interesse, os governos continuam tomando decisões sobre situações-problema e desenhando políticas para enfrentá-las, mesmo que delegando parte de sua responsabilidade, principalmente a de implementação, para outras instâncias, inclusive não-governamentais.

Das diversas definições e modelos sobre políticas públicas, podemos extrair e sintetizar seus elementos principais:

- A política pública permite distinguir entre o que o governo pretende fazer e o que, de fato, faz.

- A política pública envolve vários atores e níveis de decisão, embora seja materializada através dos governos, e não necessariamente se restringe a participantes formais, já que os informais são também importantes.

- A política pública é abrangente e não se limita a leis e regras.

- A política pública é uma ação intencional, com objetivos a serem alcançados.

- A política pública, embora tenha impactos no curto prazo, é uma política de longo prazo. 
- A política pública envolve processos subseqüentes após sua decisão e proposição, ou seja, implica também implementação, execução e avaliação.

\section{O papel das instituições/regras na decisão e formulação de políticas públicas}

Não só a produção desenvolvida dentro da moldura teórica específica da política pública é utilizada nos seus estudos. 0 debate sobre políticas públicas também tem sido influenciado pelas premissas advindas de outros campos teóricos, em especial do chamado neo-institucionalismo, que enfatiza a importância crucial das instituições/regras para a decisão, formulação e implementação de políticas públicas.

U ma grande contribuição a esse debate foi dada pela teoria da escoIha racional pelo questionamento de dois mitos. 0 primeiro é o de que, conforme mencionado acima, interesses individuais agregados gerariam ação coletiva (O Ison, 1965). O segundo é o de que a ação coletiva produz necessariamente bens coletivos (Arrow, 1951). D efinições sobre políticas públicas são, em uma democracia, questões de ação coletiva e de distribuição de bens coletivos e, na formulação da escolha racional, requerem o desenho de incentivos seletivos, na expressão de $\mathrm{O}$ Ison, para diminuir sua captura por grupos ou interesses personalistas. ${ }^{13}$

O utros ramos da teoria neo-institucionalista, como o institucionalismo histórico e o estruturalista, também contribuem para o debate sobre o papel das instituições na modelagem das preferências dos decisores. Para estas variantes do neo-institucionalismo, as instituições moldam as definições dos decisores, mas a ação racional daqueles que decidem não se

13 Para uma revisão dessa literatura, ver, entre outros, Levi (1997), e para uma discussão da aplicação de tipologias na análise de políticas públicas tomando como referência a teoria da escolha racional, ver, entre outros, O strom (1999). 
Sociologias, Porto Alegre, ano 8, no 16, jul/dez 2006, p. 20-45

restringe apenas ao atendimento dos seus auto-interesses. A ação racional também depende das percepções subjetivas sobre alternativas, suas conseqüências e avaliações dos seus possíveis resultados. Sem negar a existência do cálculo racional e auto-interessado dos decisores, esses ramos do neoinstitucionalismo afirmam que o cálculo estratégico dos decisores ocorre dentro de uma concepção mais ampla das regras, papéis, identidades e idéias. ${ }^{14}$ Portanto, a visão mais comum da teoria da escolha pública, de que o processo decisório sobre políticas públicas resulta apenas de barganhas negociadas entre indivíduos que perseguem seu auto-interesse, é contestada pela visão de que interesses (ou preferências) são mobilizados não só pelo auto-interesse, mas também por processos institucionais de socialização, por novas idéias e por processos gerados pela história de cada país. O s decisores agem e se organizam de acordo com regrase práticas socialmente construídas, conhecidas antecipadamente e aceitas (M arch e O Isen, 1995: 28-29). Tais visões sobre o processo político são fundamentais para entendermos melhor as mudanças nas políticas públicas em situações de relativa estabilidade.

Já a teoria da escolha pública adota um viés normativamente cético quanto à capacidade dos governos de formularem políticas públicas devido a situações como auto-interesse, informação incompleta, racionalidade limitada e captura das agências governamentais por interesses particularistas. Essa teoria é, provavelmente, a que demonstra mais mal-estar e desconfiança na capacidade dos mecanismos políticos de decisão, defendendo a superioridade das decisões tomadas pelo mercado vis-à-vis as tomadas pelos políticos e pela burocracia.

Aprofundando um pouco mais as contribuições do chamado neoinstitucionalismo para a área de políticas públicas, sabemos que, de acordo com os vários ramos desta teoria, instituições são regras formaise informais

140 institucionalismo histórico vem dedicando espaço cada vez maior à importância das idéias na formulação de políticas públicas, em especial nas suas mudanças. Para uma análise da introdução, na Grã-Bretanha, das idéias monetaristas em substituição às keynesianas, ver Hall (1998). 
que moldam o comportamento dosatores. Como as instituições influenciam os resultados das políticas públicas e qual a importância das variáveis institucionais para explicar resultados de políticas públicas? A resposta está na presunção de que as instituições tornam o curso de certas políticas mais fáceis do que outras. Ademais, as instituições e suas regras redefinem as alternativas políticas e mudam a posição relativa dos atores. Em geral, instituições são associadas a inércia, mas muita política pública é formulada e implementada. Assim, o que a teoria neo-institucionalista nosilumina é no entendimento de que não são só os indivíduos ou grupos que têm força relevante influenciam as políticas públicas, mas também as regras formaise informais que regem as instituições.

A contribuição do neo-institucionalismo é importante porque a luta pelo poder e por recursos entre grupos sociais é o cerne da formulação de políticas públicas. Essa luta é mediada por instituições políticas e econômicas que levam as políticas públicas para certa direção e privilegiam alguns grupos em detrimento de outros, embora as instituições sozinhas não façam todos os papéis - há também interesses, como nos diz a teoria da escolha racional, idéias, como enfatizam o institucionalismo histórico e o estrutural, e a história, como afirma o institucionalismo histórico.

A despeito das contribuições das diversas vertentes da teoria neoinstitucionalista para a análise de políticas públicas, é preciso lembrar que, como ocorre com qualquer referencial teórico, é preciso ter clareza sobre quando e como utilizá-lo. Isso porque, como já argumentado anteriormente (Souza, 2003), analisar políticas públicas significa, muitas vezes, estudar o "governo em ação", razão pela qual nem sempre os pressupostos neoinstitucionalistas se adaptam a essa análise. Ademais, os procedimentos metodológicos construídos pelas diversas vertentes neo-institucionalistas, em especial a da escola racional, são marcados pela simplicidade analítica e 
Sociologias, Porto Alegre, ano 8, ํo 16, jul/dez 2006, p. 20-45

pela elegância, no sentido que a matemática dá a essa palavra, e pela parcimônia, o que nem sempre é aplicável à análise de políticas públicas. ${ }^{15}$

\section{Considerações finais}

Este trabalho buscou trazer para o debate acadêmico uma resenha da literatura (ou das literaturas) sobre um campo do conhecimento que busca integrar quatro elementos: a própria política pública, a política (politics), a sociedade política (polity) e as instituições onde as políticas públicas são decididas, desenhadas e implementadas. Disso pode-se concluir que o principal foco analítico da política pública está na identificação do tipo de problema que a política pública visa corrigir, na chegada desse problema ao sistema político (politics) e à sociedade política (polity), e nas instituições/ regras que irão modelar a decisão e a implementação da política pública.

0 entendimento dos modelos e das teorias acima resumidos pode permitir ao analista melhor compreender o problema para o qual a política pública foi desenhada, seus possíveis conflitos, a trajetória seguida e o papel dos indivíduos, grupos e instituições que estão envolvidos na decisão e que serão afetados pela política pública.

\section{Referências}

ARRO W, Kenneth. Social Choice and Individual Values. New H aven: Yale U niversity Press. 1951.

BACH RACH B, P. e BARATZ, M. S. "Two Faces of Power", American Science Review 56: 947-952. 1962.

15 Sobre os problemas e as possibilidades teóricas e empíricas da pesquisa em políticas públicas no Brasil, ver Faria (2003), Figueiredo e Figueiredo (1986), Melo (1999), Reis (2003) e Souza (2003). 
BAU GARTNER, Frank e JO N ES, Bryan. Agendas and Instability in American Politics. Chicago: University of Chicago Press. 1993

BU EN O, Luciano. "A Aplicação da Advocacy Coalition Framework (ACF) na Análise da Evolução da Política Pública de Controle de Armas no Brasil". Trabalho apresentado no GT Políticas Públicas do XXIX Encontro Anual da ANPO CS, 2529 de outubro, Caxambu: MG. 2005.

CAPELLA, Cláudia Niedhardt. “Formação da Agenda Governamental: Perspectivas Teóricas". Trabalho apresentado no GT Políticas Públicas do XXIX Encontro Anual da ANPOCS, 25-29 de outubro, Caxambu: MG. 2005

CAIDEN, N. e WILDAVISKY, A. Planning and Budgeting in Developing Countries. New York: John Wiley. 1980.

COHEN, Michael, MARCH, James e OLSEN, Johan. "A Garbage Can Model of O rganizational Choice", Administrative Science Q uarterley 17: 1-25. 1972.

DYE, Thomas D. Understanding Public Policy. Englewood Cliffs, N.J.: PrenticeHall. 1984.

EASTO NE, D. A Framework for Political Analysis. Englewood Cliffs: Prentice H all. 1965.

EVANS, Peter, RU ESCHEM EYER, D. e SKO CPO L, Theda. Bringing the State Back In. Cambridge: Cambridge U niversity Press. 1985.

FARIA, Carlos Aurélio Pimenta. "Idéias, Conhecimento e Políticas Públicas: Um Inventário Sucinto das Principais Vertentes Analíticas Recentes", Revista Brasileira de Ciências Sociais 18 (51): 21-30. 2003.

FIGUEIRED O, M arcus e FIGUEIRED O, Argelina C. "Avaliação Política e Avaliação de Políticas: U m Q uadro de Referência Teórica", Revista Fundação João Pinheiro: 108-129. 1986.

FU CKS, M ario. "Arenas de Ação e D ebate Públicos: Conflitos Ambientaise a Emergência do Meio Ambiente Enquanto Problema Social no Rio de Janeiro", Dados 41 (1): 230-245. 1998.

GOO DIN, R. e KLINGEM ANN, H-D. (eds.). New Handbook of Political Science. Oxford: Oxford University Press. 1998. 
Sociologias, Porto Alegre, ano 8, ํo 16, jul/dez 2006, p. 20-45

HALL, Peter (1998) "The M ovement from Keynsianism to M onetarism: Institutional Analysis and British Economic Policy in the 1970s", In STEIM O, S., THELEN, K. e LO NGSTRETH, F. (eds.) Structuring Politics: Historial Institutionalism in Comparative Perspective, pp. 90-113. Cambridge: Cambridge U niversity Press. 1998.

KIN GD O N, John. Agendas, Alternatives, and Public Policies. Boston: Little, Brown. 1984

LASW ELLLaswell, H.D. Politics: Who Gets What, When, How. Cleveland, M eridian Books. 1936/1958

LEVI, M argaret. "A M odel, a Method, and a Map: Rational Choice in Comparative and H istorical Analysis", In: LICHBACH, M. e ZU CKERM AN, A. (eds.) Comparative Politics: Rationality, Culture, and Structure, pp. 19-41. Cambridge: Cambridge University Press. 1997

LIN D BLO M , CharlesE. "The Science of M uddling Through", Public Administration Review 19: 78-88. 1959.

LIND BLO M, Charles E. "Still Muddling, Not Yet Through", Public Administation Review 39: 517-526. 1979

LOWI, Theodor. "American Business, Public Policy, Case Studies and Political Theory", World Politics, 16: 677-715. 1964

LO WI, Theodor. "Four Systems of Policy, Politics, and Choice". Public Administration Review, 32: 298-310. 1972.

LYN N Lynn, L. E. Designing Public Policy: A Casebook on the Role of Policy Analysis. Santa Monica, Calif.: Goodyear. 1980

MARCH, James G. e OLSEN Johan P. Democratic Governance. New York: The Free Press. 1995.

MARQ UES, Eduardo C. Estado e Redes Sociais: Permeabilidade e Coesão nas Políticas U rbanas no Rio de Janeiro. São Paulo: FAPESP; Rio de Janeiro: Revan. 2000.

MEAD, L. M. "Public Policy: Vision, Potential, Limits", Policy Currents, Fevereiro: $1-4.1995$ 
MELO, M arcus André. "Estado, Governo e Políticas Públicas". In: M ICELI, S. (org.). O que Ler na Ciência Social Brasileira (1970-1995): Ciência Política. São Paulo/ Brasília: Sumaré/Capes. 1999.

O LSO N, Mancur. The Logic of Collective Action. Cambridge, Mass.: Harvard University Press. 1965.

OSTROM M, Elinor. "An Assessment of the Institutional Analysis and Development Framework". In: SABATIER, Paul (ed.). Theories of the Policy Process. Boulder: Westview Press. 1999.

PARSO NS, Wayne. Public Policy: An Introduction to the Theory and Practice of Policy Analysis. Cheltenham: Edward Elgar. 1997.

PETERS, B. G. American Public Policy. Chatham, N.J.: Chatham House. 1986.

PETERS, B. G. The Politics of Bureaucracy. White Plains: Longman Publishers. 1995.

PETERS, B. G. "Review: Understanding Governance: Policy Networks, Governance, Reflexivity and Accountability by R. W. Rhodes", Public Administration 76: 408-509. 1998.

PINTO , Isabela Cardoso de M atos. Ascensão e Q ueda de uma Q uestão na Agenda Governamental: $\mathbf{O}$ Caso das 0 rganizações Sociais da Saúde na Bahia. Tese de Doutorado em Administração do Núcleo de Pós-Graduação em Administração da U FBA. 2004.

REIS, Elisa. "Reflexões Leigas para a Formulação de uma Agenda de Pesquisa em Políticas Públicas", Revista Brasileira de Ciências Sociais 18 (51): 21-30. 2003.

SABATIER, Paul (ed.). Theories of the Policy Process. Westview: Westview Press. 1999.

SABATIER, Paul e JEN KINS-SMITH, Hank. Policy Change and Learning: The Advocacy Coalition Approach. Boulder: Westview Press. 1993.

SIMO N, Herbert. Comportamento Administrativo. Rio de Janeiro: USAID. 1957.

SO UZA, Celina. "Políticas Públicas: Q uestões Temáticas e de Pesquisa”, Caderno CRH 39: 11-24. 2003. 
Sociologias, Porto Alegre, ano 8, ํo 16, jul/dez 2006, p. 20-45

THEOdOULOU, S. e CAHN, M. Public Policy: The Essential Readings. New Jersey: California State U niversity. 1995.

WILDAVSKY, Aaron. The Policy of Budgetary Process. Boston: Little and Brown, 2edição. 1992. 
Sociologias, Porto Alegre, ano 8, o 16, jul/dez 2006, p. 20-45

\section{Resumo}

0 artigo apresenta uma revisão dos principais conceitos e modelos de formulação e análise de políticas públicas, buscando sintetizar o estado-da-arte da área, ou seja, mapear como a literatura clássica e a mais recente tratam o tema. 0 artigo busca, também, discutir as possibilidades aplicativas das diferentes vertentes das teorias neo-institucionalistas à análise de políticas públicas.

Palavras-chave: políticas públicas, modelos de formulação e análise de políticas públicas, teorias $\mathrm{Neo}$-Institucionalistas.

Recebido: $15 / 05 / 06$

Aceite final: 18/07/06 


\section{ABSTRACTS}

Sociologias, Porto Alegre, ano 8, no 16, jul/dez 2006, p. 368-375

Public Policies: a Literature Review

Celina Souza

The article presents a review of the main concepts and models for making and assessment of public policies, seeking to synthesize the state of the art in the field, that is, to map how classic and more recent literature approach the subject. The article also seeks to discuss possibilities for application of distinct streams of neo-institutionalist theories to the assessment of public policies.

Key words: Public policies, M odels for Making and Assessment of Public Policies, Neo-Institutionalist Theories. 